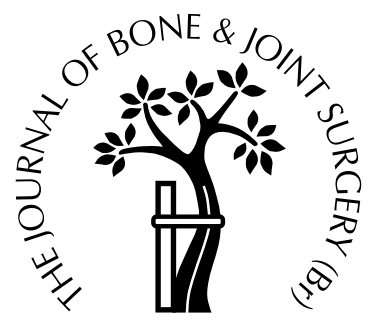

\title{
Dislocation after total hip replacement in relation to metal-on-metal bearing surfaces
}

\author{
M. T. Clarke, P. T. H. Lee, R. N. Villar \\ From the BUPA Cambridge Lea Hospital and the University of Cambridge, England
}

M etal-on-metal (MOM) is a commonly used bearing notable for its 'suction fit' when lubricated. In this study, we examined the capacity for MOM bearings to protect against dislocation after total hip replacement (THR).

We undertook a clinical investigation to compare the rate of dislocation of MOM bearings with those of ceramic-on-polyethylene (COP) bearings and found that one MOM bearing dislocated in a series of 109 hips $(0.9 \%)$ compared with nine of 145 hips $(6.2 \%)$ in the COP group $(p=0.02)$.

We also performed an in vitro investigation comparing the peak forces generated during forced separation of the two bearings of the same dimensions at velocities from 1 to $50 \mathrm{~cm} / \mathrm{s}$. This revealed that the MOM bearing generated significant resistance to separation at all velocities (maximum mean $24 \mathrm{~N}$ ), whereas the COP did not (maximum mean $1.9 \mathrm{~N}, \mathrm{p}<0.001$ ). We conclude that MOM bearings are more stable to dislocation than COP bearings as a result of the interfacial forces provided by a thin, lubricating fluid.

J Bone Joint Surg [Br] 2003;85-B:650-4.

Received 11 April 2002; Accepted 13 February 2003

Primary total hip replacement (THR) is a common procedure which is complicated by dislocation in up to $10 \%$ of cases. $^{1-4}$ There are many factors which influence the inci-

M. T. Clarke, FRCSI (Trauma \& Orth), Assistant Professor

University Department of Orthopaedic Surgery, SUNY-Upstate Medical Center, 4400 University Hospital, 750 East Adams Street, Syracuse, NY 13210, USA.

P. T. H. Lee, MRCS, Clinical Research Associate

Orthopaedic Research Unit, Addenbrookes Hospital, Cambridge University, Cambridge CB2 2QQ, UK.

R. N. Villar, FRCS, Consultant Orthopaedic Surgeon

Hip \& Knee Unit, BUPA Cambridge Lea Hospital, 30 New Road, Impington, Cambridge CB4 9EL, UK.

Correspondence should be sent to Mr M. T. Clarke.

(C)2003 British Editorial Society of Bone and Joint Surgery doi:10.1302/0301-620X.85B5.13993\$2.00 dence of dislocation relating to the patient, the surgical technique and the prosthesis. The type of bearing surface could also affect the incidence of dislocation after THR. In this regard, metal-on-metal (MOM) bearings have a 'suction-fit' which is not evident with ceramic- or metal-on-polyethylene bearings (COP, MOP). This 'suction fit' can be demonstrated visually by combining a lubricated MOM femoral head with its acetabular component (Fig. 1). The MOM bearing has interfacial adhesive forces because of the thin lubricating fluid film which forms as a result of surface absorption of proteins, highly tolerant manufacturing, low diametric clearance and a highly polished surface. This phenomenon, well known to fluid physicists, ${ }^{5}$ has recently been shown to have a direct clinical application. ${ }^{6-8}$

The opportunity to test our hypothesis arose in 1998 when the senior author (RNV) elected to change his chosen prosthesis. Before 1998, patients under the age of 70 years had been offered a $28 \mathrm{~mm}$ COP bearing surface but he became concerned about the high incidence of dislocation with this bearing. After 1998, patients in this age group were offered a MOM bearing with the femoral stem remaining the same and the acetabulum uncemented as before. This change therefore provided the opportunity to compare the early rates of dislocation in the two groups.

Having thereafter identified a significant difference in the rate of dislocation between the two groups, we sought to explain this finding by in vitro simulation. Basic information relating to the adhesive forces obtainable between the bearings in vivo was obtained on custom-made apparatus.

\section{Patients and Methods}

We registered all patients about to undergo primary THR on a computer database. Details included clinical data, the surgical procedure and postoperative complications. We included only patients under the age of 70 years who were to receive their first operation other than arthroscopy for primary osteoarthritis (OA) of the hip. Other exclusions included alcoholism and neuromuscular conditions likely to predispose to dislocation. We identified 229 patients undergoing 249 primary THRs who fulfilled the entry criteria.

Between 1995 and 1998, we offered 120 patients (140 hips) a $28 \mathrm{~mm}$ COP bearing surface. We used an uncemented, press-fit, acetabular component (Duraloc or 


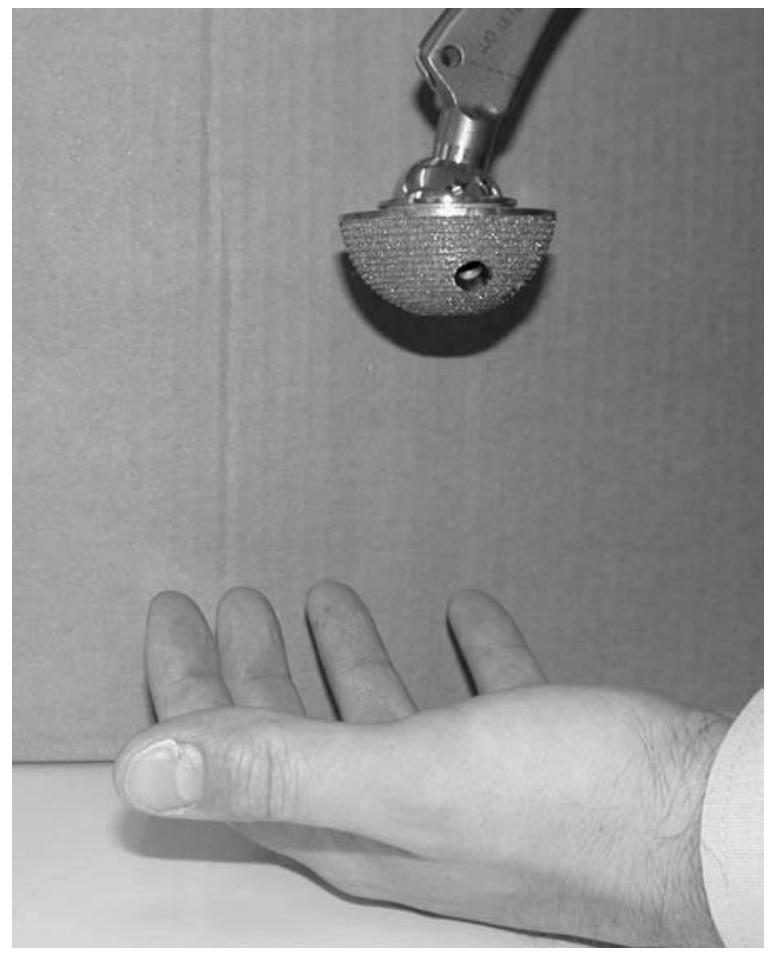

Fig. 1a

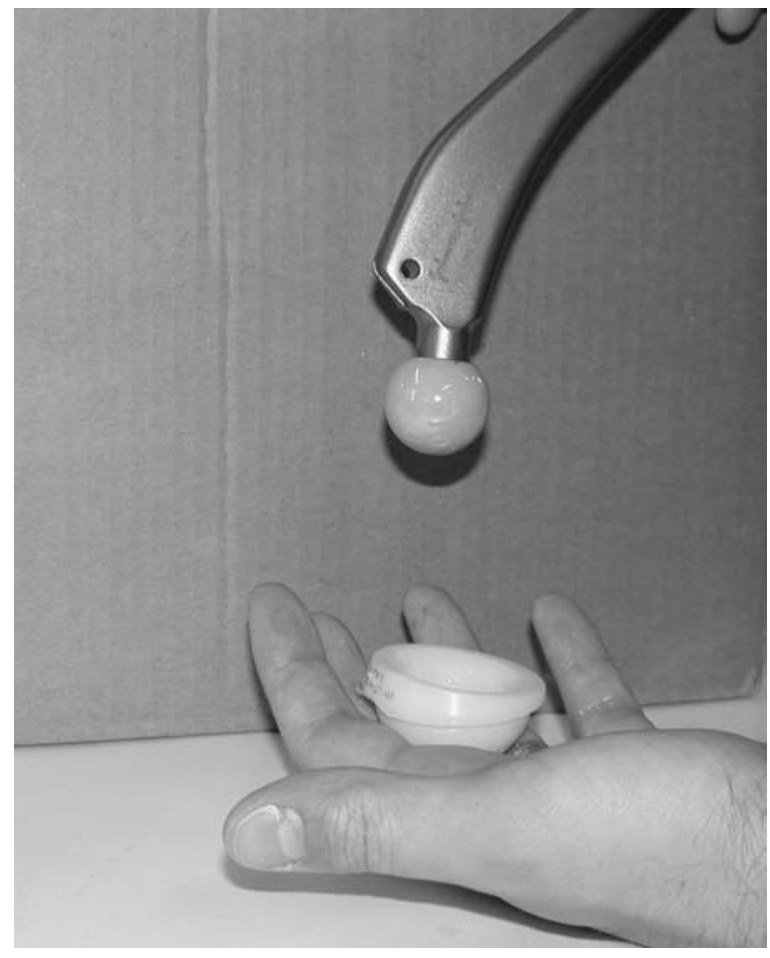

Fig. 1b

Photograph showing the ability of the MOM bearing to provide a significant 'suction fit' by pulling the acetabulum up against gravity (a). This does not occur with the COP bearing (b).

Table I. Clinical details of the patients

\begin{tabular}{|c|c|c|c|c|}
\hline & \multicolumn{2}{|l|}{ Non-dislocated } & \multirow[b]{2}{*}{$\begin{array}{l}\text { Dislocated } \\
\text { (both groups) }\end{array}$} & \multirow[b]{2}{*}{ p value } \\
\hline & $\begin{array}{l}\text { Ceramic-on- } \\
\text { polyethylene }\end{array}$ & Metal-on-metal & & \\
\hline Number of hips & 131 & 108 & 10 & \\
\hline Mean age in years (range) & $56.0(24$ to 69$)$ & 56.1 (26 to 69$)$ & 56.7 (41 to 68$)$ & 0.97 \\
\hline Mean height in cm (range) & $172.0(152$ to 196$)$ & $172.1(155$ to 205$)$ & 172.4 (152 to 183$)$ & 0.99 \\
\hline Mean weight in kg (range) & $75.7(50$ to 110$)$ & $79.3(53$ to 134$)$ & 82.7 (68 to 101$)$ & 0.07 \\
\hline BMI (range) & $25.6(18.9$ to 43.7$)$ & $26.7(19.5$ to 40.0$)$ & 27.7 (23.5 to 32.9$)$ & 0.08 \\
\hline Gender & & & & 0.83 \\
\hline Women & 64 & 57 & 5 & \\
\hline Men & 67 & 51 & 5 & \\
\hline Side & & & & 0.49 \\
\hline Left & 74 & 64 & 4 & \\
\hline Right & 57 & 44 & 6 & \\
\hline Pathology of contralateral hip & & & & 0.29 \\
\hline Normal & 85 & 58 & 7 & \\
\hline Diseased & 19 & 26 & 2 & \\
\hline THR & 27 & 24 & 1 & \\
\hline
\end{tabular}

PFC, Johnson \& Johnson, Leeds, UK) with a $10^{\circ}$ posteriorly augmented insert of ultra-high-molecular-weight-polyethylene (UHMWPE). The femoral component was the same cemented type in all cases (straight stem collarless Ultima, Johnson \& Johnson). Between 1998 and 2002, we offered 100 patients (109 hips) in the same age group a $28 \mathrm{~mm}$ cobalt-chromium-molybdenum (CoCrMo) MOM bearing. This system utilised the same cemented femoral component. The acetabular component was an uncemented, press-fit insert (Ultima MOM, Johnson \& Johnson). For all cases, we used a $10^{\circ}$ posteriorly augmented insert allowing the same arc of movement.

The same surgeon (RNV), whose technique has not changed for 14 years, performed all operations under general anaesthesia in the lateral decubitus position using the posterior approach with preservation and reattachment of the external rotators. We treated patients in bed with a Charnley wedge between the legs for the first night only and 


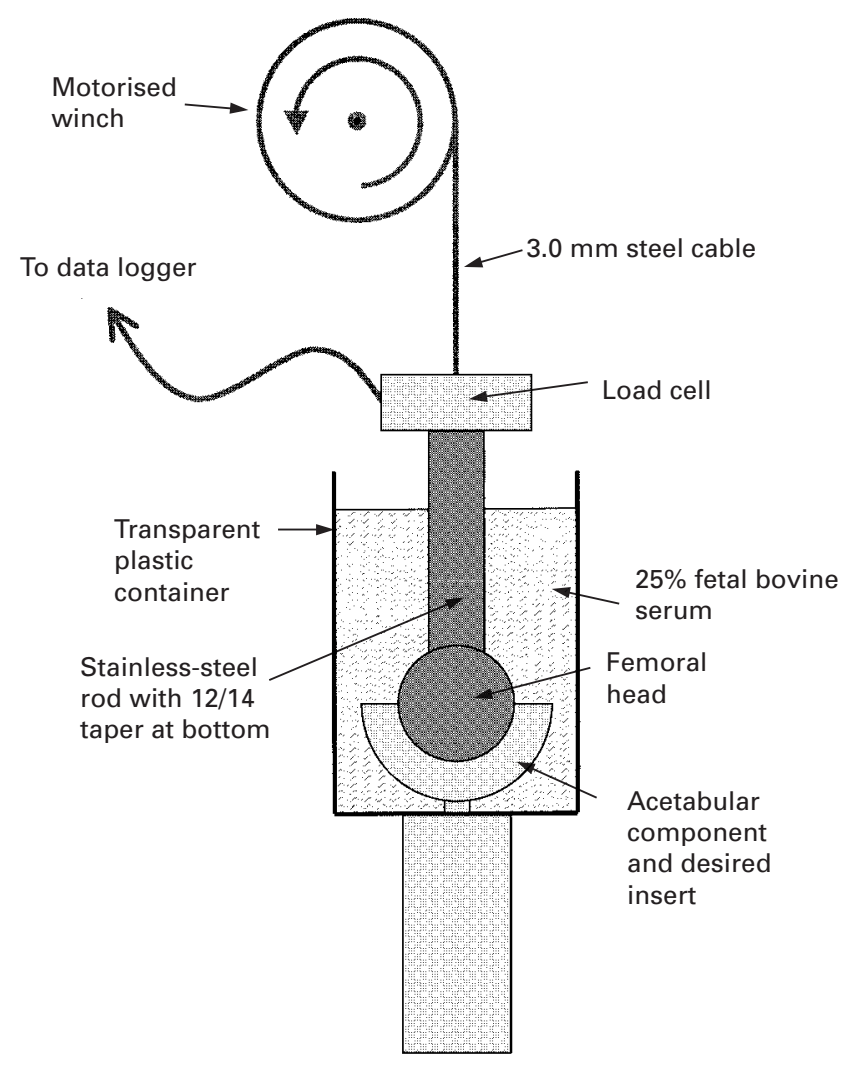

Fig. 2

Diagram of custom apparatus used to measure peak restraining forces generated at the bearing surface during separation at different velocities

they were mobilised the day after surgery. All were reviewed at six weeks and three months.

Dislocations occurring within three months of surgery were identified from the database, patient questionnaires and by telephone contact, where necessary.

Viscous tension and ionic attraction forces. A simple system was devised using a $1.5 \mathrm{~kW}$ geared, variable velocity motor (Bonfiglioli Motors, Warrington, UK) as a winch providing near instantaneous distraction velocities to our requirement (Fig. 2). We found no published data upon which to base the distraction velocities, and we therefore assumed that, with the hip and knee flexed to $90^{\circ}$, internal rotation of the limb around the femoral axis would produce impingement between 2 and $5 \mathrm{~cm}$ from the centre of the femoral head and subsequent dislocation. This range covers impingement of the neck of the prosthesis on the acetabular insert as well as trochanteric impingement on the anterior margin of the true acetabulum. We estimated the maximum velocity of separation of the femoral head from the cup by first estimating the maximum velocity at which the foot could travel during a clinical episode of dislocation. The calculation was derived in this manner for two reasons. First, the angular velocity of both regions is identical, making the calculation simple. Secondly, we found the velocity of the foot to be the easiest to measure, being the most distal part of the limb. Using an impingement distance of $5 \mathrm{~cm}$, an estimated maximum foot velocity of $300 \mathrm{~cm} / \mathrm{s}$ and a tibial length of $50 \mathrm{~cm}$, we calculated a maximum separation velocity of the femoral head of $30 \mathrm{~cm} / \mathrm{s}$. To ensure complete coverage of this range, we chose to investigate the restraining forces at 1, 5, 10, 25 and $50 \mathrm{~cm} / \mathrm{s}$ for the bearings used clinically in our study.

We attached the motorised winch to a $1.0 \mathrm{kN}$ load cell (RDP Electronics, Surrey, UK). This was connected in series to a stainless-steel bar with a 12/14 taper machined at one end. This allowed modular heads to be easily exchanged during experimentation. The metal acetabular components were held firmly by their central screw threads on to a separate steel column. The entire articulation was submerged in $25 \%$ fetal bovine serum at $37^{\circ} \mathrm{C}$ to prevent surface tension (air-liquid interface) effects which do not occur in vivo. The maximum restraining force obtained was recorded by a digital data logger (E735; RDP Electronics) attached to the load cell. The force on the components below the load cell during distraction experiments without lubrication was subtracted from the figures obtained during lubricated experiments to give a numerical result which equated with the force generated by the lubricant alone. The experiments were repeated ten times and the mean derived for each bearing.

Statistical analysis. We compared variables in patient and prosthesis factors. We used the chi-squared test for categorical data relating to gender, side of operation, pathology of the contralateral hip, stem size, acetabular size and subjective assessment of surgical difficulty. We used analysis of variance (ANOVA) for identifying differences in the mean age, height, body mass index (BMI) and acetabular inclination angles. We also used ANOVA to identify differences in the mean peak forces required to separate the bearings in the in vitro studies. Where a significant finding was identified, we used Student's $t$-test with Bonferroni correction to examine intra- and intergroup differences. We chose a significance level of 0.05 or below.

\section{Results}

As shown in Table I, the patient groups were well matched with no significant differences in mean age $(\mathrm{p}=0.97)$, height $(\mathrm{p}=0.99)$, weight $(\mathrm{p}=0.07)$, BMI $(\mathrm{p}=0.08)$, gender $(p=0.83)$, side of surgery $(p=0.49)$ and pathology of the contralateral hip $(\mathrm{p}=0.29)$. There were no significant differences between groups when comparing the size of the femoral stem $(\mathrm{p}=0.38)$ or cup $(\mathrm{p}=0.91)$, the acetabular inclination angle $(\mathrm{p}=0.26)$ and subjective difficulty of surgery $(p=0.96)$ (Table II). Since the radiographs of one patient (patient 5) had been destroyed, we were unable to include them in the statistical analysis of acetabular inclination angles.

For the MOM bearing, one of 109 prostheses dislocated within three months of surgery $(0.9 \%, 95 \%$ CI 0 to 2.7$)$, compared with nine of $140(6.4 \%, 95 \%$ CI 2.3 to 10.5$)$ in the COP group within the same time interval after surgery 
Table II. Details of the components inserted and subjective assessment of difficulty of the procedures

\begin{tabular}{|c|c|c|c|c|}
\hline & \multicolumn{2}{|l|}{ Non-dislocated } & \multirow[b]{2}{*}{$\begin{array}{l}\text { Dislocated } \\
\text { (both groups) }\end{array}$} & \multirow[b]{2}{*}{ p value } \\
\hline & $\begin{array}{l}\text { Ceramic-on- } \\
\text { polyethylene }\end{array}$ & Metal-on-metal & & \\
\hline Number of hips & 131 & 108 & 10 & \\
\hline Stem size $(\mathrm{mm})$ & & & & 0.38 \\
\hline $1(7.5)$ & 61 & 63 & 8 & \\
\hline $2(8.75)$ & 40 & 26 & 1 & \\
\hline $3(10)$ & 24 & 16 & 1 & \\
\hline $4(12.5)$ & 6 & 3 & 0 & \\
\hline Acetabular size (mm) & & & & 0.91 \\
\hline 48 & 17 & 20 & 1 & \\
\hline 50 & 35 & 38 & 3 & \\
\hline 52 & 42 & 26 & 3 & \\
\hline 54 & 31 & 22 & 2 & \\
\hline 56 & 6 & 1 & 1 & \\
\hline 58 & 0 & 1 & 0 & \\
\hline Mean acetabular inclination (degrees) & 47.5 (31 to 63$)$ & 42.1 (29 to 64$)$ & $42.8(31$ to 50$)$ & 0.26 \\
\hline Subjective assessment of surgery by surgeon & & & & 0.96 \\
\hline Routine & 119 & 95 & 9 & \\
\hline Difficult & 12 & 13 & 1 & \\
\hline
\end{tabular}

Table III. Distribution and timing of dislocations identified within three months of surgery

\begin{tabular}{|c|c|c|c|c|c|c|c|c|c|}
\hline Case & $\begin{array}{l}\text { Time after } \\
\text { surgery } \\
\text { (days) }\end{array}$ & Age & Gender & Direction & $\begin{array}{l}\text { Subjective } \\
\text { difficulty of } \\
\text { surgery }\end{array}$ & $\begin{array}{l}\text { Acetabular } \\
\text { inclination } \\
\text { angle } \\
\text { (degrees) }\end{array}$ & $\begin{array}{l}\text { Stem } \\
\text { size }\end{array}$ & $\begin{array}{l}\text { Acetabular } \\
\text { design }\end{array}$ & $\begin{array}{l}\text { Acetabular } \\
\text { cup size } \\
(\mathrm{mm})\end{array}$ \\
\hline 1 & 1 & 61 & M & Posterior & Routine & 50 & 1 & Duraloc & 50 \\
\hline 2 & 1 & 55 & M & Posterior & Routine & 46 & 2 & PFC & 54 \\
\hline 3 & 2 & 41 & $\mathrm{~F}$ & Anterior & Routine & 40 & 1 & PFC & 48 \\
\hline 4 & 5 & 59 & M & Anterior & Difficult & 48 & 1 & Duraloc & 56 \\
\hline 5 & 6 & 54 & $\mathrm{~F}$ & Posterior & Routine & Unknown & 1 & Duraloc & 50 \\
\hline 6 & 6 & 59 & $\mathrm{~F}$ & Anterior & Routine & 47 & 3 & Duraloc & 52 \\
\hline 7 & 7 & 68 & M & Anterior & Routine & 40 & 1 & $\mathrm{PFC}$ & 52 \\
\hline 8 & 11 & 55 & M & Posterior & Routine & 31 & 1 & Ultima (MOM) & 54 \\
\hline 9 & 14 & 55 & $\mathrm{~F}$ & Posterior & Routine & 40 & 1 & PFC & 50 \\
\hline 10 & 14 & 60 & $\mathrm{~F}$ & Anterior & Routine & 41 & 1 & PFC & 52 \\
\hline
\end{tabular}

(Table III). This difference is statistically significant $(\mathrm{p}=0.02)$.

In vitro assessment of peak retaining forces. We identified significant differences in the peak restraining forces between the two groups at all distraction velocities chosen ( $\mathrm{p}<0.001$ ) (Fig. 3). For the MOM bearing, we recorded significant resistance to separation at all velocities. This force increased significantly between 1 and $5 \mathrm{~cm} / \mathrm{s}$ to a maximum at $10 \mathrm{~cm} / \mathrm{s}(\mathrm{p}<0.001)$, but did not increase further despite increasing distraction velocities $(p=0.75)$. The maximum singly recorded peak restraining force was $30 \mathrm{~N}$, obtained by the MOM bearing at $10 \mathrm{~cm} / \mathrm{s}$.

By contrast, the lowest forces recorded during our study were obtained with the COP bearing at $1 \mathrm{~cm} / \mathrm{s}$. These were barely detectable at $0.1 \mathrm{~N}$. As the distraction velocity was increased for the COP bearing, we noted that the peak restraining force also increased significantly ( $p<0.001)$. However, the largest forces obtained were significantly less than those recorded for the MOM bearing. The maximum mean peak force, which we obtained for the COP bearing was $4.1 \mathrm{~N}$ at $50 \mathrm{~cm} / \mathrm{s}$. At the same velocity, MOM bearings achieved a mean of $20.5 \mathrm{~N}$.

\section{Discussion}

In this study, we have shown that a rate of dislocation of $6.4 \%$ within three months of THR using a COP bearing was reduced to $0.9 \%$ by changing to a MOM bearing. The reduction in the rate of dislocation is not explained by differences in the patient population or by factors related to the surgery. The patients in both groups were well matched. The surgical technique and postoperative protocol of this singlesurgeon series have been unchanged for 14 years making the issue of a learning curve unlikely. The cemented femoral component was the same in all cases. The acetabulum was a porous-coated, uncemented, metal-backed system in all cases. No differences in acetabular or femoral prosthetic sizes were identified between the groups. Radiological review of the dislocated cases did not show any difference in the position of the component compared with those which did not dislocate and all dislocations occurred in cases where the acetabular inclination angle was within the safe zone described by Lewinnek et al. ${ }^{9}$

We acknowledge that the rate of dislocation of $6.4 \%$ in the COP group is higher than that in many reported series, 


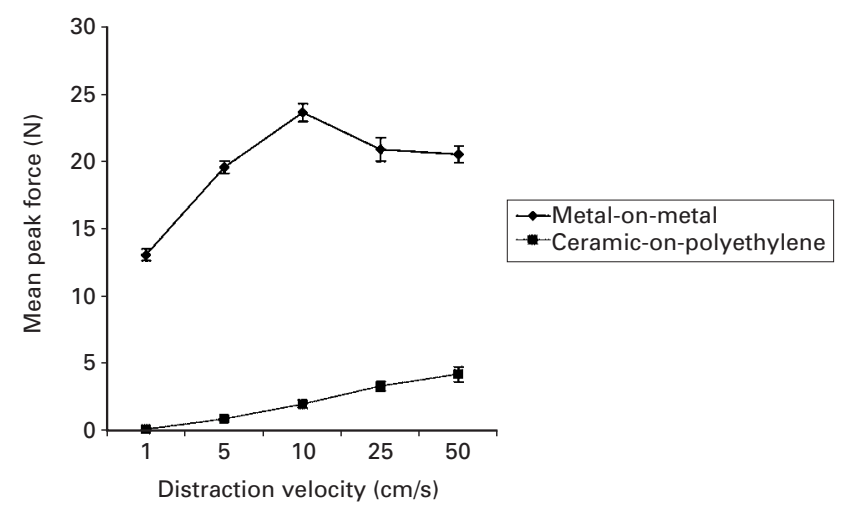

Fig. 3

Diagram showing the peak force required to separate a MOM and COP bearing when submerged in $25 \%$ calf serum lubricant at $37^{\circ} \mathrm{C}$.

but is similar to ${ }^{10,11}$ or less than others ${ }^{3,4}$ using similar prostheses inserted through a posterior approach. We believe that the importance of our results lies in the fact that the singular change to an alternative bearing surface reduced a high dislocation rate $(6.4 \%)$ to a low one $(0.9 \%)$. While these results may initially appear to be difficult to explain, we suggest a potential explanation to be the 'suction fit' seen with MOM bearings. It should be noted that all hip replacements are subject to some form of static and dynamic restraining forces as a result of the surrounding soft-tissue envelope. The 'suction fit' is an additional restraining force occurring at the bearing surface from the presence of a thin layer of fluid. The forces and equations describing them are highly complex, but well known to fluid physicists. In general, a stiff material, a thin fluid film (due to small diametric bearing clearance), a large contact area and viscous lubricating fluid will all increase the force required to separate the bearing surfaces. 5

In our in vitro tests, the MOM bearing produced a mean peak restraining force of $23.6 \mathrm{~N}$ at $10 \mathrm{~cm} / \mathrm{s}$ compared with a maximum of $4.1 \mathrm{~N}$ in the COP bearing at $50 \mathrm{~cm} / \mathrm{s}$. At lower distraction velocities, the MOM bearing maintained a significant peak mean restraining force of $13.0 \mathrm{~N}$ even at $1 \mathrm{~cm} /$ s compared with $0.1 \mathrm{~N}$ for the COP bearing. While the COP bearing displayed a linear decrease in bearing restraining force with decreasing distraction velocities, the MOM bearing did not. This would argue in favour of viscous tension being largely responsible for the small restraining forces generated in the COP bearing, but the participation of more complex ionic attraction forces generated in the MOM bearing. Whether the second of these effects occurs with ceramic-on-ceramic bearings of similar diametric clearance is, as yet, unknown, but may be important when the potential issue of micro-separation and its effects on wear during the normal gait cycle are considered..$^{6,12,13}$ If it is assumed that micro-separation is possible when there is muscle weakness or joint laxity, those bearing designs with sufficient inherent restraining force may be able to prevent its occurrence during the risk period of the swing phase in the gait cycle.

While the exact forces required for dislocation or indeed micro-separation are impossible to predict in individual cases, it is our assumption that this extra restraint is sufficient to influence the clinical experience described in this paper. In this regard, it is noteworthy that direct in vivo evidence in support of this phenomenon of fluid physics is available from videofluoroscopy studies of patients with THR in situ. ${ }^{6-8}$

Videofluoroscopy of patients having undergone replacement hip arthroplasty with a MOP bearing has shown separation of the bearing surfaces by up to $3.1 \mathrm{~mm}$ during the normal gait cycle and $5.4 \mathrm{~mm}$ during active abduction. By contrast, MOM bearings inserted by the same surgeon and approach do not separate under the same conditions. In this regard, they may be considered to have similarities to constrained bearings and the difficulty of separation has the potential therefore to reduce the incidence of dislocation.

This effect may allow MOM bearings to be more acceptable than others to minor malpositioning of the component, maintaining the stability of the femoral head within the acetabulum when other bearings would not.

No benefits in any form have been received or will be received from a commercial party related directly or indirectly to the subject of this article.

\section{References}

1. Williams O, Fitzpatrick R, Hajat S, et al. Mortality, morbidity, and 1 -year outcomes of primary elective total hip arthroplasty. J Arthroplasty 2002;17:165-76.

2. White RE Jr, Forness TJ, Allman JK, Junick DW. Effect of posterior capsular repair on early dislocation in primary total hip replacement. Clin Orthop 2001;393:163-7.

3. Vicar AJ, Coleman CR. A comparison of the anterolateral, transtrochanteric and posterior surgical approaches in primary total hip arthroplasty. Clin Orthop 1984;188:153-9.

4. Kelley SS, Lachiewicz PF, Hickman JM, Paterno SM. Relationship of femoral head and acetabular size to the prevalence of dislocation. Clin Orthop 1998;355:163-70.

5. Stefan MJ. Versuche über die scheinbare adhesion. Sitzungsberichte der mathematisch-Naturwissenschaftlichen Classe der Kaiserlichen Akademie der Wissenschaften 1874;LXIX Band II, Abtheilung Heft 1 Bis 5:713-35.

6. Dennis DA, Komistek RD, Northcut EJ, Ochoa JA, Ritchie A. "In vivo" determination of hip joint separation and the forces generated due to impact loading conditions. J Biomech 2001;34:623-9.

7. Lombardi AV Jr, Mallory TH, Dennis DA, et al. An in vivo determination of total hip arthroplasty pistoning during activity. J Arthroplasty 2000;15:702-9.

8. Dennis DA, Komistek RD, Northcut EJ, Ochoa JA, Haas B. In vivo determination of hip joint separation in subjects having either a metal-onmetal or metal-on-polyethylene total hip arthroplasty. Presented at the American Academy of Orthopaedic Surgeons' Annual meeting 2001.

9. Lewinnek GE, Lewis JL, Tarr R, Compere CL, Zimmerman JR Dislocations after total hip-replacement arthroplasties. J Bone Joint Surg [Am] 1978;60-A:217-20.

10. Li E, Meding JB, Ritter MA, Keating EM, Faris PM. The natural history of a posteriorly dislocated total hip replacement. J Arthroplasty 1999;14:964-8.

11. Woo RYG, Morrey BF. Dislocations after total hip arthroplasty. J Bone Joint Surg [Am] 1982;64-A:1295-306.

12. Tipper JL, Hatton A, Nevelos JE, et al. Alumina-alumina artificial hip joints. Part II: characterisation of the wear debris from in vitro hip joint simulations. Biomaterials 2002;23:3441-8.

13. Nevelos J, Ingham E, Doyle C, et al. Microseparation of the centers of alumina-alumina artificial hip joints during simulator testing produces clinically relevant wear rates and patterns. J Arthroplasty 2000;15:793-5. 